inherited element is only one of the components in its causation, it is worth speculating about the other cause, so that the appropriate experiments can be carried out. Three possibilities stand out.

Firstly, an autoimmune disease analogous to Hashimoto's disease of the thyroid (but if so, why does diabetes occur in patients on high doses of steroid?). Secondly, damage to the pancreas by infection, perhaps by a virus (as with mumps, but infection has, in fact, been very rarely reported). Thirdly, poisoning by a metal such as zinc or cadmium (analogous to Wilson's disease due to copper poisoning). I have some evidence from radioactive zinc studies that diabetics retain more of a dose of zinc than their spouses used as controls. I would like to suggest that experiments on the naturally occurring diabetes of dogs might be helpful. I expect that our veterinary colleagues could easily find cases of recently diagnosed diabetics and it would not be expensive to try the effect of a zinc-free diet and zinc-free water with chelation treatment to remove any metallic poisoning from the pancreas.

The inheritance of diabetes in dogs should certainly be investigated as it seems likely to be similar to the disease in humans.-I am, etc.,

\section{B. MCEvedY}

Pembury Hospital,

Tunbridge Wells,

Kent

\section{Continuous Ventilation and Oedema}

SIR,-Dr. J. T. Styles and others (29 August 1970, p. 522; 14 November, p. 431) observed marked water retention in a patient with myasthenia gravis treated with prolonged continuous mechanical ventilation. The use of a subatmospheric expiratory phase of $10 \mathrm{~cm}$ of water below ambient pressure resulted in a loss of oedema over a period of 6-8 weeks.

May I respectfully draw attention to the article entitled "Pulmonary complications and water retention in prolonged mechanical ventilation." Nineteen of the 100 patients studied developed water retention. Restriction of water intake and diuretic therapy produced a prompt improvement. Although mechanical ventilation without a subatmospheric expiratory phase was continued, repeated water retention was not observed.I am, etc.,

Arnold Sladen

Department of Anesthesiology,

University of Texas Medical School.
San Antonio, Texas, U.S.A.

1 Sladen, A., Laver, M. B., and Pontoppidan, H.

New England fournal of Medicine, 1968, 279, 448.

\section{Follow-up of Patients from an Intensive Therapy Ward}

SIR,-I was interested to read the article on "Subjective Follow-up of Patients from a Surgical Intensive Therapy Ward" by Dr. P. B. Hewitt (12 December, p. 669), particularly the conclusion that most of the patients did not find intensive care disturbing. I have also been occupied on a similar study, and would agree that most patients remember very little of their intensive care experiences, and even when they do their memory is often unreliable when compared with actual events. Dr. Hewitt states that a large percentage of her patients were postoperative cardiopulmonary bypass cases, and therefore had benefited from preoperative preparation and explanation for the intensive care interlude. Non-cardiopulmonary-bypass intensive therapy admissions do not have this benefit of preparation, and often find themselves plunged into an atmosphere of mechanized confusion when they first become aware of their surroundings; and these patients do show initial agitation, apprehension, and panic, but in my experience these patients can be satisfactorily managed by sedation, confident reassurance repeated explanation, semihypnotic suggestion, kindness, and sympathy.

In a subjective survey of 263 consecutive patients discharged alive from a multidisciplinary intensive therapy unit ${ }^{1}$ it was found that $58 \%$ of cases accepted their intensive care experiences without any untoward effect and were quite happy to talk about it. A further $27 \%$ were unable to recollect ever having been in an intensive therapy unit. A smaller group, $10 \%$, admitted having dreams, sometimes nightmares, recurring for varying periods of time following discharge. The remaining $5 \%$ could not be interviewed for various reasons.-I am, etc.,

Department of Anaesthetics,

H. G. SCHROEDER Royal Infirmary,

1 Schroeder, H. G., Anaesthesia, 1971, in press.

\section{Relapsing Prostatic Cancer}

SIR,-Mr. J. D. Fergusson's "Current Practice" articles on cancer of the prostate (21 November, p. 475, and 28 November, p. 539) prompts us to recall our therapeutic experience ${ }^{1}$ with androgens with radioactive phosphorus for patients who subsequently relapse.

Using the method of the American workers who introduced this method, 2 we have administered a two weeks' course of therapy with testosterone, adding ${ }^{32} \mathrm{P} \quad(1.8 \mathrm{mC}$ a day from day 7 to day 12) to patients who have become resistant to oestrogens and the effects of castration. Of our patients, 22 have been treated so far and 18 of them have experienced some degree of remission, with the disappearance of pain and favourable changes in bone metastases (see Table). At the beginning of our experience two patients in very poor condition died during exacerbations of pain fever, and (in one) hpyercalcaemia. This syndrome may be seen in the initial phases of treat ment but when it occurs during testosterone treatment it may be prevented from developing by giving the isotope earlier. The treatment may be repeated at an interval of a few months.

Incidence of Side Effects and Remissions

\begin{tabular}{l|c}
\hline & Total \\
\hline Nos. of Cases treated & 22 \\
Exacerbation of pain at the be- & 13 \\
ginning & 21 \\
Haematological \{ good & 1 \\
tolerance & 18 \\
Remissions (of varying degrees) & \\
\hline
\end{tabular}

The 18 remissions we obtained varied from two to eight months, and the serum acid phosphatase levels fell or rose in parallel with the clinical state. Despite some of the risks of this treatment we feel that it can delay the fatal outcome and can frequently give a valuable remission in these patients with metastatic disease, which was described in Mr. J. D. Fergusson's article (p. 540) as "probably the most difficult problem. ..." Moreover, our policy is now to give this combined treatment not only to terminal patients but also at a very early stage, a few weeks after orchidectomy, because in a period when most neoplastic deposits have already been reduced to a $\mathrm{m} \mathrm{ni-}$ mum, we hope that this hormonal-isotopic "cell kill" may get nearer to the actual eradication of the cancer.

For these earlier patients so far it is not possible to evaluate our results in terms of remission, non-remission, or cure and these will come only from a long period of followup.-We are, etc.

E. Grigoletro

M. FIORENTINO G. B. PizzI

R. VANGelista

Medical Oncotherapy Section and

Isotope Laboratory of the Radiotherapy Department, Padova City Hospital, Italy

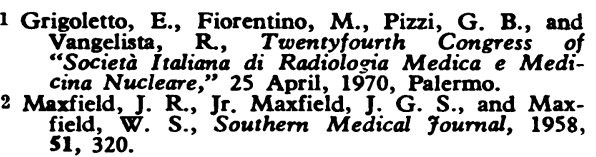

\section{Geriatric Day Hospitals}

SIR,-Your leading article on "Geriatric Day Hospitals" (16 January, p. 130) draws attention to the value of the day hospital as an essential part of a comprehensive hospital geriatric service, and rightly emphasizes its diagnostic and therapeutic role and the importance of the full rehabilitation team. The leading article on "Hospital Costing" (same issue p. 127) recommends that the efficiency of an acute hospital should be measured by the number of discharges and deaths-that is, the cost per inpatient case, and also states that by reducing the length of stay more patients can be treated at a lower cost per case.

In his book The Geriatric Day Hospital, Professor J. C. Brocklehurst has given comparative figures of total attendances at day hospitals throughout the country, rather than the total numbers of new admissions (or discharges and deaths), which provides an index of the real activity of the department concerned. A large total number of attendances with relatively few new patients is more characteristic of a day centre.

We consider that the same criteria mentioned in the leading article on hospital costing should equally well be applied to rehabilitation departments, either inpatient or day hospital. This was emphasized in a report prepared for the then Ministry of Health on day hospital costing ${ }^{2}$, when the higher cost of one day hospital compared with another was queried. It was found that in the day hospital with twice the higher costs per total number of attendances the cost per new attendance was approximately a third that of the other. It is unfortunate that the Department of Health still appears to be using the total number of attendances as a yardstick for the financing of annual running costs of day hospitals, which really only provides an index of the sum of the number of patients the day hospital building can take and the numbers of day's a week the unit is open. In a recent guidance to regional hospital boards the Department of Health suggested that financing should be based on the formula of $£ 200$ per 100 attendances. This policy can only result in encouraging the tendency to run a day hos- 
pital as a day centre, but financed from hospital revenue.

In a paper by us and C. M. Hyland ${ }^{3}$ the case was put that a day ward should not be provided by the hospital service to make up for the deficiencies of the welfare services, but should highlight these deficiencies so that they can be remedied. De Martino stressed that as long as the finance of the National Health Service is divided into hospital, general practitioner, and local authority services, it is essential that the hospital service should spend its money only to perform a hospital function.

We wish to draw the attention of those in the specialty of geriatric medicine to the fallacious reasoning and inherent dangers of the Department of Health's current method of financing day hospital running costs, which will penalize the smaller and busier day hospital with a high turnover at the expense of the larger day centre type of day hospital.-We are, etc.,

Victoria Hospital,

ANDREW FAIRLEY

West Middlesex Hospital,

JAMES ANDREWS

Brocklehurst, J. C., The Geriatric Day Hospital, London, King Edward Fund for London, 1970 Andrews, J., and Joines, D., Report of an Investigation into the Costs of the West Middlesex
and Durham Day Hospitals, 1965 , unpublished. Andrews, J., Fairley, A., and Hyland, M. Mournal of the American Geriatrics Society, 1970, 18, De Martino, J., Medica
p. 18; No. 2, p. 16 .

\section{Immunosuppressive Drugs in Rheumatoid Arthritis}

SIR,-The place of so-called immunosuppressive agents in the treatment of rheumatoid arthritis and similar diseases is now one of the most important questions in clinical immunology. Controlled trials have shown definite benefit in rheumatoid arthritis. Thus, Mason and colleagues using azathioprine in steroid-treated, late rheumatoid arthritis and a committee of the American Rheumatism Association" using cyclophosphamide in rheumatoid arthritis both obtained favourable results. Arising from these results, a statistically controlled study of cyclophosphamide, azathioprine, and sodium aureothiomallate in the treatment of the earlier stages of rheumatoid arthritis is under way. It seems important to find out if these immunosuppressive drugs are able to prevent the development of the morbid anatomical changes of rheumatoid arthritis when used in good t:me. The criteria of improversent, except the criteria of radiological improvement, are the same as those by which anti-inflammatory drugs are measured. Since at least one of the immunosuppressive drugs, namely 6 mercaptopurine, has been shown to have aspirin-like action in experimental inflammation in animals ${ }^{3}$ it seemed essential to rule out aspirin-like action in man. This question had to be answered to interpret any possible improvenient in the criteria studied in the longer term trial.

Fourteen inpatients with definite or classical rheumatoid arthritis involving the proximal interphalangeal joints took part. They had not had gold, steroid, or antimalarial treatment. Haematological indices were followed carefully. Measuremenis of grip strength, total proximal interphalangeal joint girth, and assessments of morning stiffness were made by standard methods before 9.30 a.m. on each assessment day. All patients were treated with placebo for one week. This was to establish a stable base for comparison and to allow for the non-specific improvement which often follows the admission of patients to hospital After this, patients were allocated to one of the six possible treatment sequences of the three active drugs, aloxiprin (aluminium polyoxyaspirin), azathioprine, and cyclophosphamide. Spacing placebo periods of two to five days separated the five or seven day periods on active drug to eliminate any possible carry-over from one drug to another. Azathioprine was given at a dose of $2.5 \mathrm{mg} / \mathrm{kg}$ body weight, cyclophosphamide $1.5 \mathrm{mg} / \mathrm{kg}$, and aloxiprin at $6 \mathrm{~g}$ per day. We compared the mean readings at the end of the initial period of placebo treatment with those at the end of each period of active drug treatment. Grip strength.-There were no
differences between placebo, cyclophosphamide, and azathioprine. T-tests showed a small increase $(p=0 \cdot 1)$ with aloxiprin.

foint Girth.-The total period of study was associated with a reduction in joint girth. Most of this reduction occurred in the initial period of placebo treatment. Significant further reduction $(p=0.05)$ occurred with aloxiprin but not with azathioprine or cyclopho'sphamide.

Morning Stiffness.-Assessments gave no reliable data.

Subjective Assessment.-The patient (and sometimes her nurses) noted improvement in well-being and joint symptoms on aloxiprin and deterioration on change to placebo or immunosuppressive drugs in most instances.

Thus, in this double-blind, short-term, crossover trial of azathioprine, cyclophosphamide, and aloxiprin in 14 inpatients with rheumatoid arthritis aloxiprin caused the expected improvement, the other drugs little or none. We conclude that any benefits shown by immunosuppressive drugs in longterm treatment of rheumatoid arthritis are unlikely to be a reflection of an antiinflammatory "aspirin-like" action, even though such actions have been demonstrated in experimental animals.-We are, etc.,

A. ST. J. Dixon D. J. LINDSAY E. M. Collins

Royal National Hospital for Rheumatic Diseases, Bath

Mason, M., Currey, H. L. F., Barnes, C. G. Dunne, B. F., Hazleman, B. L., and Strickla American Rheumatism Association, New England Amournal of Medicine, 1970, 283, 883 .

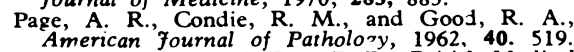
Boardman, P. L., and Hart, F. D., British Medical Fournal, 1967, 4, 264.

\section{Solubility Test for $\mathbf{H b} \mathbf{S}$}

SIR,-A rapid and highly reliable screening test for the presence of $\mathrm{Hb} \mathrm{S}$ in whole blood is available as a commercial kit. ${ }^{1}$ Exactly comparable results can be obtained by the following method, which is based on the original observations of Itano. ${ }^{2}$

A $2.24 \mathrm{M}$ buffer at $\mathrm{pH} 6.7$ is made as follows:
$\mathrm{K}_{2} \mathrm{HPO}_{4}, 220.3 \mathrm{~g} ; \mathrm{KH}_{2} \mathrm{PO}_{4}, 132.45 \mathrm{~g}$; saponin $5 \mathrm{~g}$; water to $1,000 \mathrm{ml}$. Put $10 \mathrm{mg}$ of sodium dithionite $\left(\mathrm{Na}_{2} \mathrm{~S}_{2} \mathrm{O}_{4}\right)$ into a small test-tube (exact measurement is not required after the appearance of $10 \mathrm{mg}$ has been appreciated). Add $1 \mathrm{ml}$ of buffer and mix. Introduce $0.02 \mathrm{ml}$ of whole blood (from a $\mathrm{Hb}$ pipette) and mix. Normal blood produces a clear purplish-red solution after 3-5 min; AS, SC, and SS bloods give a cloudy precipitate. The cost of the chemicals to provide 1,000 tests is about $8 \mathrm{~s}$.

There are circumstances in which it migh be advantageous to distinguish AS from $S S$ blood. This can be done by the use of a $1.8 \mathrm{M}$ buffer, (conveniently prepared from the preceding one by adding $2 \mathrm{ml}$ of water to $8 \mathrm{ml}$ buffer, which gives a $1.79 \mathrm{M}$ buffer). When a buffe: of this strength is used in the test AS blood is soluble, while SS blood gives a precipitate; the reading is not quite as easy as with the standard test but definite enough to act as preliminary screen. If the suspected SS blood is known to have a low $\mathrm{Hb}$ level, it is advisable to add two $0.92 \mathrm{ml}$ amounts in the test. It is also wise to include known positive and negative controls.

Fuller details will be presented later. ${ }^{3}-$ I am, etc.,

A. B. RAPER

Department of Pathology,
Bristol Royal Infirmary, Bristol Ballard, M. M. S., Radel, E., Sakhadeo,
Shorr, J. B., fournal of Pediatrics, 1970,
76, Itano, H. A. Archives of Biochemistry and
Biophysics, i953, 47, 148. Biophysics, 1953, 47, 148.
Cook, A., and Raper, A. B., in press.

\section{Obesity and Respiratory Infection in Children}

SIR,-May I correct the statement made by Dr. V. V. Tracey and his colleagues (2 January, p. 16), in which they state that I used the 70 th weight percentile as a criterion of obesity in infants. In the paper to which they refer calculations were made using the accepted definition of obesity as "a weight which exceeds the mean weight for height and sex by $20 \%$ or more"; in terms of percentiles this would be equivalent to the 90th percentile or greater, the figure used by $\mathrm{Dr}$. Tracey and colleagues, who chose the alternative criterion of obesity.

I am also surprised that they should think that there is little published work to confirm or disprove the clinical impression of the relationship between obesity in infants and respiratory infection. May I briefly summarize the findings of studies in this area?!

A retrospective study of 345 infants admitted to hospital with lower respiratory infection showed that infants who were obese required more antispasmodic drug therapy, but were less severely affected than those who were of average weight. Obese infants comprised $30 \%$ of the number of infants admitted with lower respiratory infection. A prospective study comprised the study of 200 infants at intervals between 1 month and 1 year old. Ninety-five per cent of infants were examined at home; data were recorded on each visit of the weight, height, subcutaneous fat thickness, respiratory infections, and feeding. The main findings were: of the 200 infants $176(88 \%)$ had respiratory infections, $41(20 \%)$ had lower respiratory infections. There were 459 infections in the 200 infants, of which $62(13.5 \%)$ were lower respiratory. Male infants showed a significant increase in lower respiratory infections compared with females $(P<0 \cdot 01)$.

There was a significant increase in the proportion of infants with infection who weighed $2.5 \mathrm{~kg}$ or less at birth, compared with those over 